\title{
Schools and Terrorism: Global Trends, Impacts, and Lessons for Resilience
}

\author{
Elisaveta P. Petkova ${ }^{a}$, Stephanie Martinez ${ }^{a}$, Jeffrey Schlegelmilch ${ }^{a}$, and Irwin Redlener ${ }^{a, b}$ \\ ${ }^{a}$ National Center for Disaster Preparedness, Earth Institute, Columbia University, New York, NY, USA; \\ ${ }^{b}$ Department of Health Policy and Management, Mailman School of Public Health, Columbia University, \\ New York, NY, USA
}

\begin{abstract}
This study characterizes trends in the frequency and characteristics of terrorist attacks in child-serving educational institutions around the world, examining the specific vulnerabilies of children and schools with regard to terrorist violence, as well as the various impacts that violence has on children, communities, and societies. Following the analysis of available data on terrorist attacks against educational institutions, vulnerabilities, and impacts, the study concludes with a discussion of what still needs to be understood in the intersection of child vulnerability and terrorism, and provides recommendations for improving resilience to terrorist attacks against child-serving educational institutions.
\end{abstract}

\section{ARTICLE HISTORY}

Received 23 June 2016

Accepted 9 August 2016

One would like to think that certain truths or values would be universally understood as rules of engagement, formally declared or otherwise. The sanctity of children's well-being should be unquestioned, regardless of the issues at stake in the larger conflict. Sadly, history shows that this understanding is neither universally shared nor uniformly valued.

Since the violent attack on School Number One in Beslan, Russia in 2004, the perceived threat of massive terror attacks targeting schoolchildren has loomed in the public consciousness. In recent years, attacks against educational institutions worldwide have increasingly been reported and documented. The kidnapping of 276 schoolgirls by Boko Haram in Nigeria and the massacre of at least 150 students and staff in a Peshawar school by the Pakistani Taliban in 2014 are still fresh in the minds of the public. These attacks serve as reminders of the vulnerability that children in schools face, being "soft targets" whose symbolic value has the capacity of invoking mayhem at the largest possible scale. They also demonstrate the urgency with which this emerging trend in violence must be systemically recorded, analyzed, and mitigated.

The following article will discuss the vulnerability of children with regard to terrorist violence, exploring the literature on what makes children and educational institutions

CONTACT Elisaveta P.Petkova epp2109@columbia.edu N National Center for Disaster Preparedness, Earth Institute, Columbia University, Suite 303, 215 West 125th Street, New York, NY 10027, USA.

Color versions of one or more figures in the article can be found online at www.tandfonline.com/uter. 
particularly desirable targets. Trends in the frequency and characteristics of terrorist attacks against child-serving educational institutions around the world will be examined, paying particular attention to potential school level and gendered disparities. Finally, a critical analysis on what can be learned from the available data and what still needs to be researched in the nexus of child vulnerability and terrorism will be provided.

\section{Remembering the Horror at Beslan}

To fully understand the terror and chaos that can be created when a school is attacked, it takes looking no further back than to the violence that befell School Number One in 2004 . 1 September was supposed to be a celebratory day in Beslan, as students and families in the Russian town arrived on campus for the first day of the school year. But the events that began that Wednesday and that would continue into the following two days eventually became one of the nation's worst experiences with terrorism. At the onset of the attack, shots rang out as armed militants, part of a Chechen separatist group, ${ }^{2}$ forced over 1,200 children, parents, grandparents, and teachers into the gym. The facility was then rigged with bombs, some with the forced help of older male students. That afternoon, two groups of male hostages were executed by the assailants. During the next 48 hours, hostages suffered hunger and dehydration while being kept in the gym. On the final day, the school became a bloody battleground, as medical workers approaching the facility to remove bodies lying in front of the school were shot dead, followed closely by two explosions. The gym roof collapsed, killing many of those who were trapped inside. ${ }^{3}$ Hostages began escaping from the school, as further fighting ensued between the militants and soldiers outside. ${ }^{4}$ By nighttime, the attack was over. One-hundred and eighty-six children were killed. ${ }^{5}$

\section{The Vulnerability of Soft Targets}

Public spaces of evocative symbolic value are among the most likely of terror targets, ${ }^{6}$ and child-serving schools fit the bill to a tee. Bradford and Wilson ${ }^{7}$ suggest that children and educational institutions may be particularly vulnerable to terrorism because they are "soft targets"-typically unguarded sites of congregation that provide an opportunity for mass casualties. They add that the tendency for schools in particular to be unguarded, compared to a public space such as an airport, add to their unique vulnerability. Beyond their symbolic value, schools may also be subject to targeting because of the services that they are typically prepared or expected to provide. School facilities themselves can become centers of recovery during non-terror events, ${ }^{8}$ making their destruction strategic as well as symbolic.

Attacks against soft targets are also designed to generate high media visibility and provoke a strong public emotional response. Terrorist organizations crave media attention and glory, ${ }^{9}$ and may seek to leverage media coverage as a way to legitimize and bring sympathetic attention to their cause. ${ }^{10}$ British Prime Minister Margaret Thatcher once infamously urged news organizations to resist giving terrorists the "oxygen of publicity." 11 Through mediums such as news coverage, terrorists thrive by being able to foster an exaggerated image of their threat, forcing the public to believe that the government is incapable of protecting them. ${ }^{12}$ As such, some studies suggest that democracies may be particular targets of terrorism. Indeed, if the success and objective of a terrorist attack hinges on the public demanding some sort of change in line with the assailants' desires, democracies are the most logical targets. ${ }^{13}$ Large-scale 
terrorist attacks against children in schools in democratic nations thus have the capacity to quickly erode the public's confidence in their government's ability to protect this particularly vulnerable demographic, and can raise large-scale, public demands for immediate actions. ${ }^{14}$

\section{Tracking Trends in School Terrorism}

There is no consensus of what precisely constitutes terrorism. To characterize trends in terrorist acts against child-serving educational institutions, this study has utilized the database developed by the National Consortium for the Study of Terrorism and Responses to Terrorism (START) at the University of Maryland and has relied on the definition used by the group. To meet their definition, terrorist attacks in the database were required to match at least two of the following three criteria: (a) the act of violence was geared toward attaining a political, economic, religious, or social end; (b) the act of violence had evidence of an intention to coerce, intimidate, or convey some other message to a larger audience other than those immediately affected; and (c) the act of violence was outside the precepts of International Humanitarian Law. ${ }^{15}$

START's database includes publicly available information from open sources, including news archives, other data sets, and secondary source materials. The database was chosen as the basis of this analysis because of consortium's designation as a Department of Homeland Security Center of Excellence, and for its comprehensiveness. The original dataset coded for attacks against educational institutions but did not code for school type. Because the focus of this analysis is on terrorism against children in schools, the database entries were further coded by school grade level (secondary, junior, primary, etc.) if the level was explicitly indicated in the description of the attack. If an attack did not describe the level of school but identified targets as boys, girls, boys schools, girls schools, or schoolchildren, these data were included. Attacks against universities, individuals, individual educators, administrators, and non-school-aged children, as well as attacks that did not provide sufficient information to identify if they were targeting a child-serving institution, were excluded. For discussions on gender targeting, the data were further disaggregated to examine attacks against gender-specific schools and populations. The information presented in this study is limited by what documentation was publicly available. Thus, any analyses are meant to be a conservative representation of general patterns based on publically available reports, rather than absolute counts of terror attacks against children in schools.

\section{Terrorism Against Children in Schools}

Schools have been a target of terrorists for decades. For instance, during the $1974 \mathrm{Ma}$ alot massacre in Israel, more than 115 people, the majority of whom were students, were taken from the Netiv Meir Elementary School in Ma'alot. Twenty-two children were killed and 68 injured. ${ }^{16}$ Recently, the Aahan Dara Girls School in Afghanistan was suspected to have fallen victim to a poisoning attack in 2012, when over 100 schoolgirls were admitted to a hospital with reports of headaches, dizziness, and vomiting. It was one in a series of poisoning attacks against girl-serving educational institutions. ${ }^{17}$ Even with optimal intelligence and counterterror efforts, it is virtually impossible to ensure the elimination of soft target terror events, even in a country like the United States, which may have more robust monitoring systems in place. The data that were extracted from the database in fact show that attacks that target 


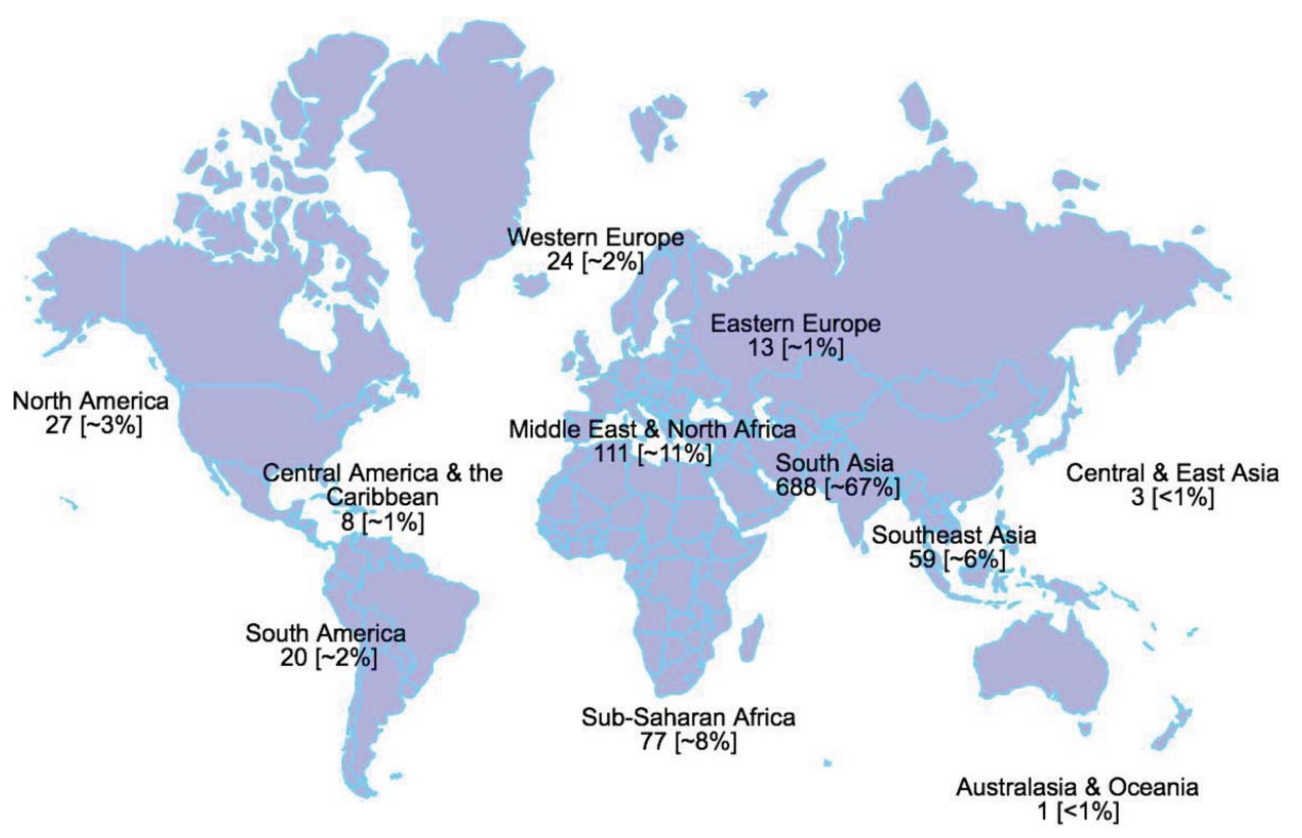

Figure 1. Distribution of attacks against children's educational institutions, 1970-2014. Data source: National Consortium for the Study of Terrorism and Responses to Terrorism (START).

schools, school-based activities (such as field trips or paths students use to walk to school), or school-affiliated infrastructure (such as schoolbuses or playgrounds) have been on the rise globally since the 1970s.

\section{Global Patterns}

Understanding how the number of reported incidents breaks down by region is critical in giving context to wider trends seen in terrorist attacks against children in schools. Afghanistan and Pakistan alone account for a significant portion of the attacks in the datasetalmost 61 percent. The burden of violence carried by South Asia should come as little surprise given the instability seen in the region in the last two decades. Trailing far behind are the Middle East and North Africa (11 percent), and sub-Saharan Africa (8 percent).

\section{Trends over Time}

While Figure 1 provides a snapshot of the regional distribution of the total number of school-targeted terror attacks between 1970 and 2014, Figure 2A depicts this trend over time. Until the mid-2000s, there was a fluctuating but consistent and relatively low number of attacks against child-serving educational institutions. Particularly in the 1970s, several of these included racially charged U.S.-based attacks by White extremists opposing integration and groups such as the Chicano Liberation Front. However, starting in the mid-2000s, the data illustrate a substantial surge in the number of reported incidents. The 213 attacks reported between 2005 and 2009 rival the 170 that took place during the preceding 35 years. Again, this analysis does not intend to conflate reports with actual incidence, but the 


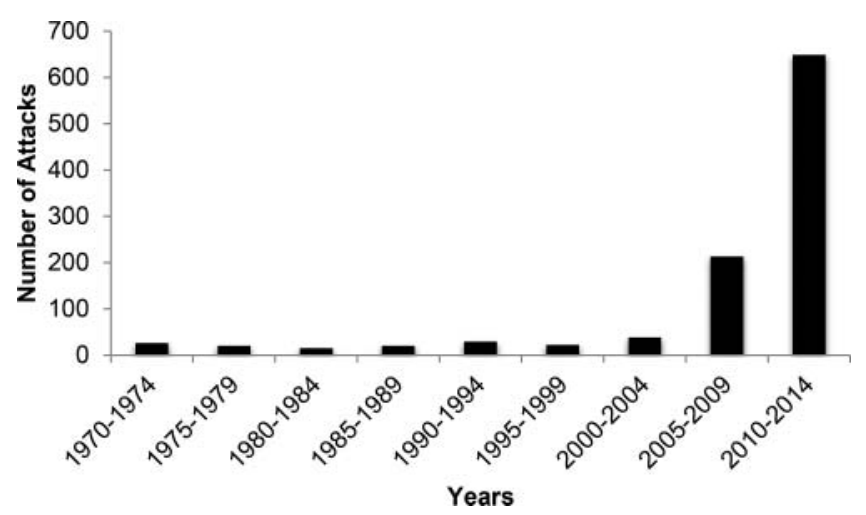

Figure 2A. Global attacks against children's educational institutions, 1970-2014. Data source: National Consortium for the Study of Terrorism and Responses to Terrorism (START).

dramatic spike presented in Figure $2 \mathrm{~B}$ at the very least urgently invites further research. In the most recent period alone, between 2010 to 2014, the number of terrorist incidents involving child-serving schools has already surpassed the previous 5 years, threefold.

\section{The Nature of Terrorist Attacks Against Children in Schools}

\section{Types of Attacks}

Understanding the methods used by assailants in attacking children in schools may be of use to policymakers and others who have the capacity to recognize or prevent an attack before it occurs. Bombing by explosives, bombs, and dynamite was overwhelmingly the attack strategy of choice. Over 70 percent of the reported school attacks were primarily perpetrated using this method. One interesting observation was the emergence of toxic chemicals as primary weapons. Among the 27 instances of terrorist acts where chemicals were used as the main weapon, 21 occurred in Afghanistan, 4 in Vietnam, and 1 in China and Ukraine, respectively. All of these types of attacks took place after 1997, and the majority occurred

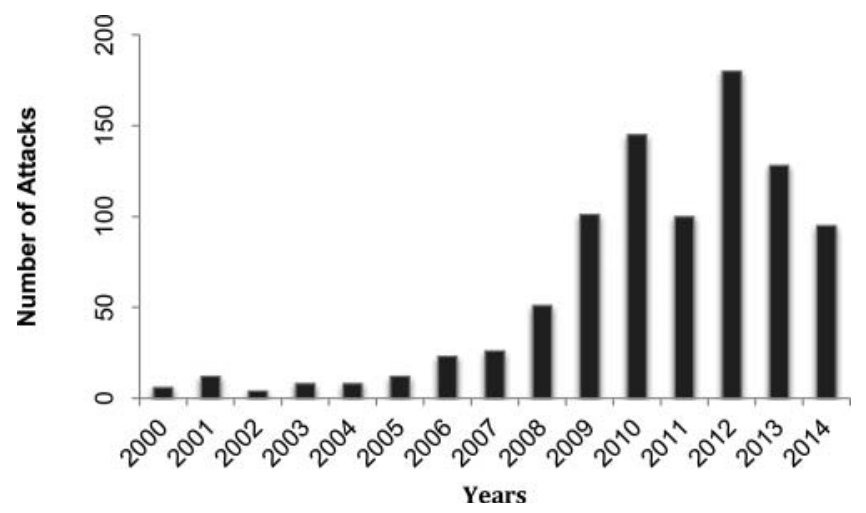

Figure 2B. Global attacks against children's educational institutions, 2000-2014. Data source: National Consortium for the Study of Terrorism and Responses to Terrorism (START). 


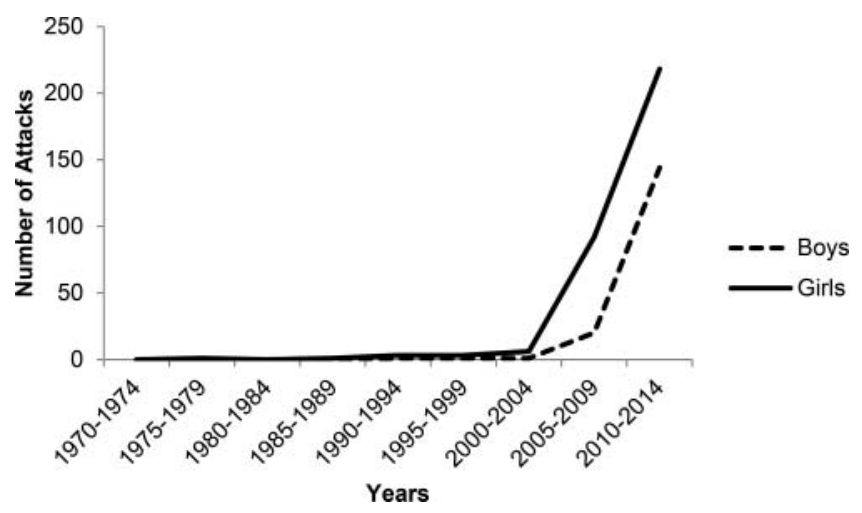

Figure 3. Attacks against girls and boys in educational institutions, 1970-2014. Data source: National Consortium for the Study of Terrorism and Responses to Terrorism (START).

after 2006. Nineteen of the 27 attacks were perpetrated against girl-only schools or explicitly targeted girl students. All of these girl-centered chemical attacks took place in Afghanistan.

\section{Gender Specificity of Attacks}

The use of chemical attacks against girl-serving educational institutions is just one aspect of the gender disaggregated data. The information also showed that since the mid-2000s, girls schools appear to be targeted more often than boys schools. Figure 3 shows that attacks against schools serving only boys or only girls remained relatively stable, low, and comparable until the period between 2000 and 2004. From then on, the incidences of school-based attacks against both sexes soared. Between 2005 and 2009, schoolgirls and girls schools faced 92 attacks, while schoolboys and boys schools faced 20. In the next five years, those numbers rose to 218 for girls and 144 for boys. In total, since 1970, girls in schools have been the victims of 324 attacks, and boys 167.

It is problematic to interpret the gap as a clear indication that girls schools tend to be more targeted than boys schools. While the data capture incidents where girls schools were attacked by extremists because of disapproval of female education, they also capture many schools that just happened to exclusively teach female students.

\section{School Types and Attacks}

Of all the terrorist attacks included in the disaggregated dataset, primary schools emerged as the institutions facing the most violence, with a total of 451 attacks between 1970 and 2014 . Secondary schools followed close by, with 253 attacks. Figure 4 shows the breakdown of institutional attacks, looking also at associated infrastructure such as playgrounds and school vehicles. Again, similar to the gender gap, it is difficult to say from the data whether primary schools are purposefully targeted more often than secondary or middle schools. Perhaps there are simply more primary schools than secondary schools, or perhaps they tend to be near other municipal buildings that are targets of terrorism as well. What the data do show is that children at every level of schooling are at some degree of risk. 


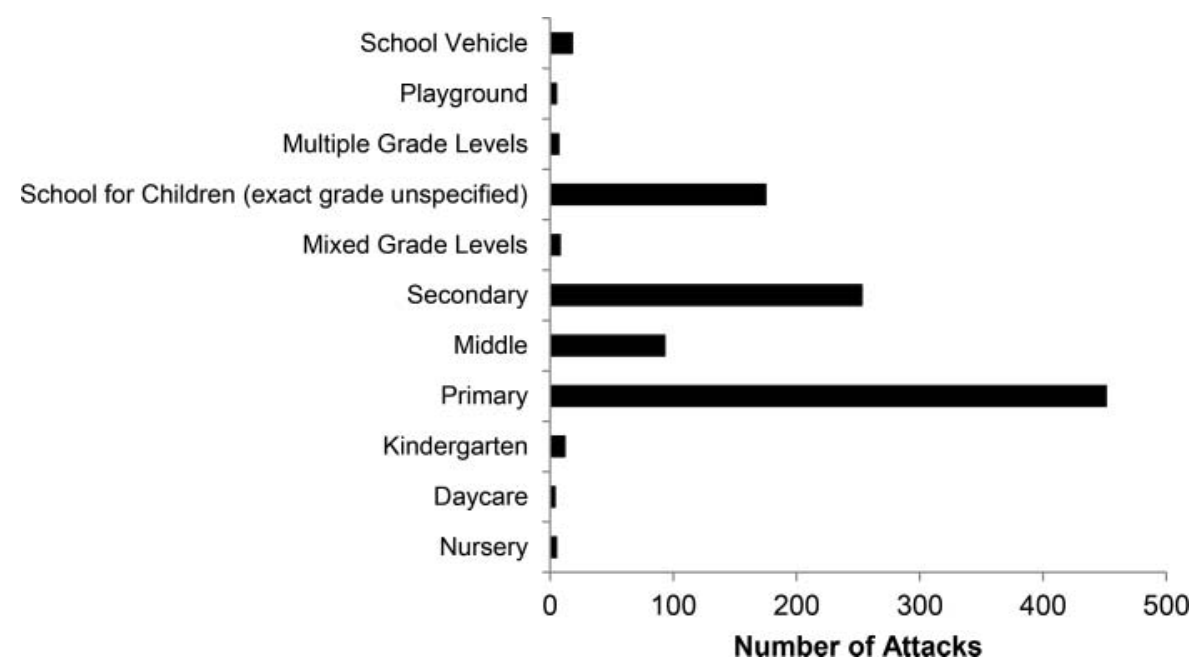

Figure 4. Global attacks against children's educational institutions, by school level, 1970-2014. Data source: National Consortium for the Study of Terrorism and Responses to Terrorism (START).

\section{Psychological Impacts of Terrorism Exposure on Children}

In addition to considering the objective threat of violence against children in schools, the impact of terrorist activities on children who survive or witness events are equally as critical to understand. If terrorism is the ideological planting of the seeds of fear, there is no ground more fertile than the minds of children. The psychological impacts among children in the wake of terrorism and traumatic events are well documented in the United States. Direct experience, proximity, and media exposure to terrorist events have a powerful impact on children. ${ }^{18}$ Children's responses to these traumatic events can manifest through acute stress disorders, depression, anxiety, separation problems, sleep difficulties, behavioral problems, and posttraumatic stress disorder (PTSD). ${ }^{19}$ Six months following the 11 September 2001 attacks in New York City, approximately 75,000 public school children in grades 4 through 12 (including those not directly affected by the attacks) had the disorder. ${ }^{20}$ Similarly, nearly a year after the 1995 Oklahoma City bombing in the United States, 50 percent of local elementary school students reported clinical levels of PTSD. ${ }^{21}$ As attacks against schools continue to rise in the face of a more wired world and a more tech-savvy global terrorist network, it is important to keep in mind the potentially serious impacts on children resulting from even indirect exposure to terrorism.

Due to the lack of empirical research in the subject area, it is difficult to conclusively describe the specific effects of terrorism on children. ${ }^{22}$ As Garbarino and Kostelny note, the body of research and clinical observations surrounding the adverse ways that children in social crises such as war cope is growing. ${ }^{23}$ In studies of violence and children, one fundamental element that has been identified as a key factor in understanding the affects of terrorism on children is classifying the violence as either chronic or acute (191). ${ }^{24}$ An acute event, such as an attack on a school in an otherwise conflict-free area, might require only situational adjustment, as the child can expect life to return to normal eventually. Yet chronic dangers, such as living in a refugee camp or war zone with continued terrorist attacks, might require a more permanent form of developmental adjustment. ${ }^{25}$ This is especially relevant, as several of the acts of terror in our dataset occurred in the context of prolonged regional conflicts. 
Another critical consideration is that varying age groups may also differ in the way they interpret the violence around them. ${ }^{26}$ Whereas young children might not fully comprehend the situation, and adolescents can slip into adopting ideology as a coping strategy, older children may be stuck in a developmental and compromising in-between. They may understand the magnitude of a terrorist attack more than a young child, but lack the tools for societal engagement to cope and move forward. ${ }^{27}$ The bulk of the attacks analyzed in the previous sections occurred in primary schools. The older cadre of these child victims, as well as the students who attended the 93 targeted middle schools, may easily fall into the older child age range.

In light of the current climate of fear surrounding the potential of terrorist attacks in the United States and other countries, further understanding of how children perceive terrorism and their own risks will be critical. On the day following the terrorist attack in San Bernardino, California on 2 December 2015, teachers in the area were provided with a guide on how to help children understand what was happening. ${ }^{28}$ One of the resources, a tipsheet provided by the National Association of School Psychologists, underscored the importance of establishing a sense of normalcy and security according to the needs of each developmental echelon. ${ }^{29}$ As the landscape of threat and exposure continues to evolve, it will be critical to better understand how terrorism and perceived susceptibility to terror attacks affects children in the present and over time.

\section{Other Long-Term Impacts}

\section{Fear of Reprisal}

When schools come under attack or are temporarily closed after destruction, children may miss out either temporarily or permanently on their education. Understandably, some parents might choose to pull their students out of school for fear of safety. But if the specter of further attacks is present, this may also lead to chronic teacher and staff shortages as adults are disincentivized to enter an employment market where their lives are constantly at risk. $^{30}$ Schools may just become empty shells, and cease to function as institutions. As several of the attacks in this analysis occurred in low-resource regions of the world with already weak education infrastructure, the implications of a generation of lost educators and a rising population of children who have significantly missed out on primary education could mean detrimental outcomes for the future of the country. The symbolic value of an attack against a school is matched only by its potentially long-term destructive value.

\section{Future Research Needs}

This article highlighted the rising numbers of attacks against schools globally, and discussed the particular vulnerabilities of children, as well as the substantial psychological and other long-term impacts of exposure to terrorism on children and their communities. Given the dynamic and evolving nature of school terrorism and the special vulnerability of children, there is an urgent need to create a robust and continuously updated global database of attacks against child-serving educational institutions. As mentioned before, the data that were used in this analysis were limited by the methodology of the original START database, whose purpose was to track terror incidents globally based on publicly available materials. For conflicts that are not in the spotlight and for regions of the world with weak education infrastructure, it is easy to imagine terror attacks against schools failing to be reported. To be useful, this education database would need to collect 
information on the attackers and identify a way to standardize school levels across countries to examine risk by age group. It should also collect more granular information concerning unique characteristics of the school (single-sex, military, nearby municipal buildings), assess whether a certain demographic was being targeted, and find a systematic way of identifying the primary and secondary motives of the attack.

Additionally, the international community, as well as scholars and practitioners focused on terrorism response and preparedness, would benefit from a body of work documenting the recovery, outcoming monitoring, and resilience strategies of those communities who have already been affected by violence. Although conflicts across countries are as heterogeneous as the schools and students they affect, some of the knowledge and actions may be applicable globally or at specific geographic locations. An effort to develop a series of case studies based on previous attacks would also be immeasurably important for policymakers in preparing for school readiness and having optimal preparedness plans in place. As an additional resource, organizations who have worked extensively in education security such as the Global Coalition to Protect Education from Attack have developed recommendations that may be of use for policymakers looking for concrete ways to better protect their educational institutions. Finally, insufficient attention has been devoted to date to establishing active collaborations between schools and various city, state, and governmental agencies. Only a few studies have provided useful assessments of the level of preparedness among schools ${ }^{31}$ and among emergency medical services agencies ${ }^{32}$ and nurses ${ }^{33}$ and the topic has received insufficient attention in recent years. Due to the ever-present nature of the threat against educational institutions, ensuring optimal school-preparedness is of critical importance in preventing and responding to terrorism.

In conclusion, the influx in reports of mass violence against children in school requires immediate attention from researchers and policymakers in order to fully understand the risk profile of children and schools as popular strategic targets for terrorists, and what can reasonably be done to address their vulnerabilities. Special attention must be made in collecting detailed data on attacks, documenting successful resilience strategies, and establishing active collaborations between schools and various city, state, and governmental agencies. As the security landscape continues to change day-by-day, the urgency with which this topic must be further researched has never been greater.

\section{Funding}

This project was funded by the Alfred P. Sloan Foundation and the Children's Health Fund.

\section{Notes}

1. Irwin Redlener, Americans at Risk: Why We Are Not Prepared for Megadisasters and What We Can Do Now (New York: Knopf, 2006), p. 111.

2. Nikolay Korzhov and Andrey Kovalenko, "In Pictures: The Beslan Massacre, 10 Years On," Al Jazeera English, 1 September 2014. Available at http://www.aljazeera.com/indepth/inpictures/ 2014/05/pictures-beslan-massacre-10-yea-201452295058690132.html (accessed 23 June 2016).

3. Ibid.

4. Kelly McEvers, "Beslan Timeline: How the School Siege Unfolded," NPR, 31 August 2006. Available at http://www.npr.org/templates/story/story.php?storyId = 5740009 (accessed 23 June 2016).

5. CNN Library, "Beslan School Siege Fast Facts," CNN, 31 August 2015. Available at http://www. cnn.com/2013/09/09/world/europe/beslan-school-siege-fast-facts/ (accessed 23 June 2016). 
6. Alex Braithwaite, "The Logic of Public Fear in Terrorism and Counter-Terrorism," Journal of Police and Criminal Psychology 28 (2013), pp. 95-101.

7. Emma Bradford and Margarey Wilson, "When Terrorists Target Schools: An Exploratory Analysis of Attacks on Educational Institutions," Journal of Police and Criminal Psychology 28 (2013), pp. 127-138.

8. Brenda Greene, Lisa Barrios, Joy Elizabeth Blair, and Lloyd Kolbe, "Schools and Terrorism: A Supplement to the Report of the National Advisory Committee on Children and Terrorism," The Journal of School Health 74(2004), pp. 39-51.

9. Louise Richardson, What Terrorists Want: Understanding the Enemy, Containing the Threat (New York: Random House, 2006).

10. Raphael Perl, Terrorism, the Media, and the Government: Perspectives, Trends, and Options for Policymakers (Washington, DC: UNT Digital Library, 1997). Available at http://digital.library. unt.edu/ark:/67531/metacrs419/ (accessed 23 June 2016).

11. R. W. Apple Jr., "Thatcher Urges the Press to Help 'Starve' Terrorists," New York Times, 15 July 1985. Available at http://www.nytimes.com/1985/07/16/world/thatcher-urges-the-press-to-helpstarve-terrorists.html (accessed 23 June 2016).

12. CNN Library, "Beslan School Siege Fast Facts."

13. Ibid.; William Eubank and Leonard Weinberg, "Does Democracy Encourage Terrorism?," Terrorism and Political Violence 6 (1994), pp. 17-43; William Eubank and Leonard Weinberg, "Terrorism and Democracy: What Recent Events Disclose," Terrorism and Political Violence 10 (1998), pp. 108-118; William Eubank and Leonard Weinberg, "Terrorism and Democracy: Perpetrators and Victims," Terrorism and Political Violence 13 (2001), pp. 155-164.

14. CNN Library, "Beslan School Siege Fast Facts."

15. National Consortium for the Study of Terrorism and Responses to Terrorism (START). "Data Collection Methodology." Available at http://www.start.umd.edu/gtd/using-gtd/ (accessed 23 June 2016).

16. Sue Fishkoff, "Documentary Recalls the Horrors of Ma'alot School Massacre," Jewish Telegraphic Agency, 5 May 2011. Available at http://www.jta.org/2011/05/05/arts-entertainment/documen tary-recalls-the-horrors-of-maalot-school-massacre (accessed 23 June 2016).

17. Masoud Popalzai, "Official: 160 Girls Poisoned at Afghan School," CNN, 29 May 2012. Available at http://www.cnn.com/2012/05/29/world/asia/afghanistan-girls-poisoned/ (accessed 23 June 2016).

18. Wanda Fremont, Caroly Pataki, and Eugene Berestin, "The Impact of Terrorism on Children and Adolescents: Terror in the Skies, Terror on Television," Child and Adolescent Psychiatric Clinics 14 (2005), pp. 429-451.

19. Ibid.

20. Ibid.

21. American Psychological Association, "The Impact of Terrorism and Disasters on Children." Available at http://www.apa.org/about/gr/issues/cyf/disaster.aspx (accessed 23 June 2016).

22. Deborah Browne, "Examining the Impact of Terrorism on Children," in Andrew Silke, ed., Terrorists, Victims and Society: Pschological Perspectives on Terrorism and its Consequences (West Sussex, England: John Wiley \& Sons, 2003).

23. James Garbarino and Kathleen Kostelny, "Children's Response to War: What Do We Know?," in Lewis Leavitt and Nathan Fox, eds., The Psychological Effects of War and Violence on Children (New York, NY: Psychology Press, 2014), pp. 23-29.

24. Browne, "Examining the Impact of Terrorism on Children."

25. Garbarino and Kostelny, "Children's Response to War."

26. Browne, "Examining the Impact of Terrorism on Children."

27. Ibid.

28. Sonali Kohli, "What San Bernardino Teachers Are Doing to Help their Students Cope," Los Angeles Times, 3 December 2015. Available at http://www.latimes.com/local/education/ community/la-me-edu-san-bernardino-shooting-teachers-help-students-cope-20151203-story.html (accessed 23 June 2016).

29. National Association of School Psychologists, "Talking to Children About Violence: Tips for Parents and Teachers." Available at https://www.nasponline.org/resources-and-publications/ 
resources/school-safety-and-crisis/school-violence-prevention/school-violence-prevention-tipsfor-parents-and-educators (accessed 23 June 2016).

30. Global Coalition to Protect Education from Attack, "Education Under Attack 2014." Available at http://protectingeducation.org/sites/default/files/documents/eua_2014_full_0.pdf (accessed 23 June 2016).

31. Martin, Shelly D., Anneke C. Bush, and Julia A. Lynch, "A National Survey of Terrorism Preparedness Training Among Pediatric, Family Practice, and Emergency Medicine Programs," Pediatrics 118 (2006), pp. e620-e626; Graham, James, Steve Shirm, Rebecca Liggin, Mary E. Aitken, and Rhonda Dick, "Mass-Casualty Events at Schools: A National Preparedness Survey," Pediatrics 117 (2006), pp. e8-e15.

32. Graham, James, Rebecca Liggin, Steve Shirm, Brian Nation, and Rhonda Dick, "Planning for a Mass Casualty Incident in Arkansas Schools," The Journal of School Health 75 (2005), pp. 327-328.

33. Robert P. Olympia, Erin Wan, and Jeffrey R. Avner, "The Preparedness of Schools to Respond to Emergencies in Children: A National Survey of School Nurses," Pediatrics 116 (2005), pp. e738-3745. 